\title{
Effects of Acute Systemic Hyperinsulinemia on Forearm Muscle Proteolysis in Healthy Man
}

\author{
Paolo Tessari, Sandro Inchiostro, Gianni Biolo, Ezio Vincenti, ${ }^{\star}$ and Luigi Sabadin \\ With the technical assistance of Monica Vettore \\ Department of Metabolic Diseases, and *Department of Anesthesiology, University of Padova, 35128 Padova, Italy
}

\begin{abstract}
To investigate the mechanism(s) of insulin-induced suppression of plasma amino acid concentration and release, we studied forearm as well as whole-body leucine and phenylalanine uptake and release during a peripheral insulin infusion in postabsorptive normal subjects using isotope-dilution methods. Before insulin, leucine and phenylalanine release exceeded uptake $(P<0.01$ and $P<0.07$, respectively). A net output of $\alpha$-ketoisocaproate (KIC) was also observed. During insulin, arterial plasma leucine, KIC and phenylalanine concentrations decreased $(P<0.05$ or less vs. basal), despite ongoing net output of these substrates by the forearm, that persisted after correction for the mean transit time spent through the extracellular muscular space. By the end of insulin, whole-body leucine and phenylalanine concentrations and rate of appearance were decreased $(P<0.01$ vs. basal). However, release and uptake of both amino acids by the forearm were not significantly decreased vs. the preinsulin values. These data indicate that systemic hyperinsulinemia acutely decreases plasma amino acid concentrations by acting primarily at sites other than skeletal muscle. (J. Clin. Invest. 1991. 88:27-33.) Key words: amino acid uptake $\bullet$ amino acid release $\cdot$ leucine rate of appearance • phenylalanine rate of appearance $\bullet$ net amino acid output
\end{abstract}

\section{Introduction}

The mechanisms by which insulin influences amino acid as well as protein turnover in vivo have been investigated with isotope dilution techniques in the last years, both in the whole body and at organ level (1-7). While there is a general agreement on the effect of the hormone to decrease whole-body rate of appearance $\left(R_{\mathrm{a}}\right)^{1}$ of essential amino acids and therefore of proteolysis (1-7), the organs and/or tissues responsible for this effect have been less clearly identified. In a pioneering study (1), infusion of insulin into the portal bed so as to mimic the physiologic infusion route decreased leucine concentration

This work was presented in abstract form at the 26th Meeting of the European Association for the Study of Diabetes, Copenhagen, 10-13 Sept. 1990.

Address correspondence to Dr. Paolo Tessari, Cattedra di Malattie del Ricambio, Istituto di Medicina Clinica, Policlinico Universitario, via Giustiniani 2, 35128 Padova, Italy.

Received for publication 16 July 1990 and in revised form 3 December 1990

1. Abbreviations used in this paper: AUC, areas under the curve; KIC, $\alpha$-ketoisocaproate; MTT, mean transit time; $R_{\mathrm{a}}$, rate of appearance.

J. Clin. Invest.

(c) The American Society for Clinical Investigation, Inc. 0021-9738/91/07/0027/07 \$2.00

Volume 88, July 1991, 27-33 and its rate of appearance by decreasing liver and splanchnic release of this amino acid (1). However, since skeletal muscle represents the most abundant deposit of body proteins, it is of major interest to investigate the effects of hyperinsulinemia also at this level. In a recent study (8) the infusion of insulin directly into the brachial artery with no systemic perturbation of amino acid and hormone concentrations decreased the net negative balance of two essential amino acids (leucine and phenylalanine) across the forearm, exclusively by inhibiting proteolysis (8). This experimental approach, designed to investigate the effects of insulin per se on skeletal muscle, may be not considered physiological, since insulin is normally delivered into the splanchnic bed and thereafter into the systemic circulation. Thus, its overall effects on plasma amino acid levels and turnover are the result of simultaneous metabolic actions on a variety of tissues and organs. An infusion of the hormone into the peripheral vascular bed with generalized hyperinsulinemia accompanied by changes of plasma amino acid and other substrate concentrations may elicit a different response at the level of skeletal muscle.

To address this question, we have investigated the effects of a systemic increase of plasma insulin levels on leucine and phenylalanine concentrations and kinetics in healthy man, using the forearm model as a mirror of skeletal muscle metabolism. The arterial-deep venous catheterization technique was combined with the peripheral infusion of $\left[{ }^{3} \mathrm{H}\right]$ phenylalanine and $\left[{ }^{14} \mathrm{C}\right]$ leucine tracers. Since phenylalanine is not metabolized by muscle (9-11), its uptake represents incorporation into protein, while its release reflects proteolysis. As opposed to phenylalanine, the metabolism of leucine is more complex, because of the extensive and rapid interconversion of this amino acid with its $\alpha$-ketoanalogue, $\alpha$-ketoisocaproate (KIC) $(12,13)$. Moreover, skeletal muscle is a site, even if to a different extent, of both a transaminase and an oxidative activity for this amino acid and KIC (14). Therefore, as regards leucine, only estimates of uptake and release by the forearm are presented, with no conclusions about its oxidative as well as nonoxidative utilization.

\section{Methods}

Isotopes. $\mathrm{L}-\left[2,6-{ }^{3} \mathrm{H}\right]$ phenylalanine $(50 \mathrm{Ci} / \mathrm{mmol})\left(\left[{ }^{3} \mathrm{H}\right]\right.$ phenylalanine $)$ and $\mathrm{L}-\left[1-{ }^{14} \mathrm{C}\right]$ leucine $(55 \mathrm{mCi} / \mathrm{mmol})\left(\left[{ }^{14} \mathrm{C}\right]\right.$ leucine $)$ were purchased from Amersham Int'l., Amersham, UK. The isotopes were purified by HPLC and found to be $92-94 \%$ pure. Actual isotope infusion rates were corrected accordingly. All isotopes were proven to be sterile and pyrogen free before use.

Experimental design. Seven male healthy volunteers (age, 22-30 yr; body mass index, 22-25) were admitted to our metabolic unit after the overnight fast. The protocol was explained in detail to each subject, who signed a written consent to the study. The study was part of a more comprehensive protocol previously submitted and approved by the competent authorities of the local medical faculty. Polyethylene cath- 
eters were placed percutaneously into the brachial artery and, in a retrograde fashion, into an ipsilateral deep vein until the tip of the catheter was no longer palpable under the skin (15). This vein drained predominantly blood from the muscle tissue (15). An additional catheter was placed into an antecubital vein of the opposite arm for isotope, insulin, and glucose infusions. A primed continuous infusion of $\left[{ }^{3} \mathrm{H}\right]-$ phenylalanine and $\left[{ }^{14} \mathrm{C}\right]$ leucine was then started by means of a calibrated pump (Harvard Apparatus Co., Inc., The Ealing Corp., S. Natick, MA). Priming doses were $\sim 20$ times (for phenylalanine) and 30 times (for leucine) the corresponding continuous infusion rate per min. Isotope infusion rates are reported in Table I. Venous plasma samples were taken every $30 \mathrm{~min}$ (data not shown) to assess the achievement of steady-state conditions of plasma substrate concentrations and radioactivities, effectively attained $2 \mathrm{~h}$ after the start of isotope infusions (Figs. 1 and 2). Thereafter, four arterial and deep venous samples were withdrawn almost simultaneously at 10 -min intervals over 30 min. The arterial samples were taken $10-20 \mathrm{~s}$ after the deep venous ones to prevent an acute hypoperfusion of the forearm vascular bed. An unprimed continuous insulin infusion at the rate of $0.05 \mathrm{U} /$ $\mathrm{m}^{2} \cdot$ min was then started. The insulin solution was prepared as described elsewhere (5). Blood glucose was maintained at the basal, euglycemic levels by means of appropriate $20 \%$ dextrose infusions. Arterial and deep venous samples were then taken after $15,30,45,60,90,120$, $150,160,170$, and $180 \mathrm{~min}$ from the start of the insulin infusion. Two additional samples for the measurement of plasma flow were taken both before and by the end of the insulin infusion. $5 \mathrm{~min}$ before the withdrawal of each blood sample, the circulation of the hand was excluded by means of a pediatric sphingomanometer inflated at 170-180 mmHg.

Analytical measurements. Blood was collected into EDTA tubes and rapidly centrifuged at $4^{\circ} \mathrm{C}$. The plasma was then stored at $-20^{\circ} \mathrm{C}$

Table I. Isotope Infusion Rates, Forearm Plasma Flow, SteadyState Substrate ( $\mu \mathrm{mol} / \mathrm{liter})$, and Isotope (DPM/ml) Concentrations, in Arterial and in Deep Venous Plasma before and after Insulin Infusion

\begin{tabular}{clcr}
\hline & & Before insulin & After insulin \\
\hline $\begin{array}{c}\text { Forearm plasma flow } \\
(\mathrm{ml} / \mathrm{kg} \cdot \mathrm{min})\end{array}$ & & & \\
$\begin{array}{c}\text { Concentrations } \\
\text { Leucine }\end{array}$ & $\mathrm{A}$ & $140 \pm 4$ & $33.2 \pm 3.4$ \\
& $\mathrm{dV}$ & $145 \pm 5^{\ddagger}$ & $95 \pm 4^{*}$ \\
KIC & $\mathrm{A}$ & $40 \pm 2$ & $94 \pm 4^{*}$ \\
& $\mathrm{dV}$ & $43 \pm 2^{\ddagger}$ & $25 \pm 2^{*}$ \\
Isoleucine & $\mathrm{A}$ & $42 \pm 2$ & $26 \pm 2^{*}$ \\
& $\mathrm{dV}$ & $47 \pm 4^{\ddagger}$ & $16 \pm 2^{*}$ \\
Phenylalanine & $\mathrm{A}$ & $44 \pm 5$ & $17 \pm 2^{*}$ \\
& $\mathrm{dV}$ & $48 \pm 5^{5}$ & $29 \pm 3^{*}$ \\
Radioactivity & & & $30 \pm 3^{*}$ \\
{$\left[{ }^{14} \mathrm{C}\right]$ leucine } & $\mathrm{A}$ & $316 \pm 51$ & \\
& $\mathrm{dV}$ & $258 \pm 36^{\ddagger}$ & $193 \pm 32^{* \ddagger}$ \\
{$\left[{ }^{14} \mathrm{C}\right] \mathrm{KIC}$} & $\mathrm{A}$ & $68 \pm 11$ & $51 \pm 10^{*}$ \\
& $\mathrm{dV}$ & $64 \pm 11$ & $44 \pm 9^{* \ddagger}$ \\
{$\left[{ }^{3} \mathrm{H}\right]$ phenylalanine } & $\mathrm{A}$ & $511 \pm 103$ & $422 \pm 82^{*}$ \\
& $\mathrm{dV}$ & $425 \pm 81^{\ddagger}$ & $321 \pm 50^{* \ddagger}$ \\
Isotope infusion rates & & & \\
$(\mathrm{DPM} / \mathrm{kg} \cdot \mathrm{min})$ & & & \\
{$\left[{ }^{14} \mathrm{C}\right]$ leucine } & & $4197 \pm 508$ & \\
{$\left[{ }^{3} \mathrm{H}\right]$ phenylalanine } & & $7708 \pm 747$ & \\
& & &
\end{tabular}

${ }^{*} P<0.01$, after vs. before insulin; ${ }^{\ddagger} P<0.01$, arterial vs. deep venous values; ${ }^{8} P<0.07$, arterial vs. deep venous values. $A$, arterial; $d V$, deep venous.
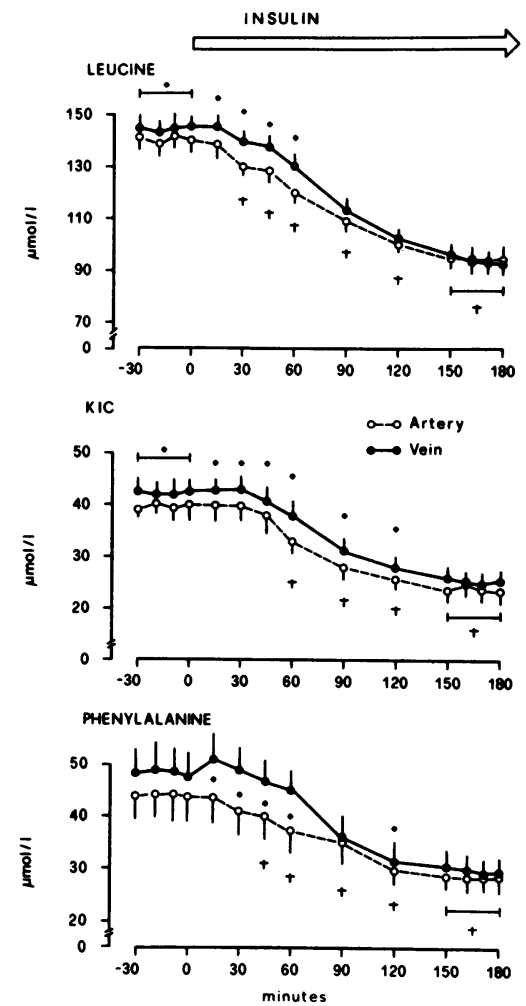

Figure 1. Plasma leucine, $\mathrm{KIC}$, and phenylalanine concentrations in the artery (open circles and dotted lines) and in the deep vein (closed circles and continued lines), before and during insulin infusion. *Statistically significant differences $(P<0.05$ or less) between arterial and deep venous values; 'statistically significant differences $(P<0.05$ or less) before vs. after the start of insulin.

before assay. Plasma leucine, isoleucine, and phenylalanine concentrations, as well as leucine and phenylalanine specific activity (SA), were determined by HPLC $(16,17)$. The original method designed for leucine assay (16) was extended also to the measurement of phenylalanine concentration and SA (17). A linear standard curve for both concentrations and absolute amounts of phenylalanine-derived phenylpyruvic
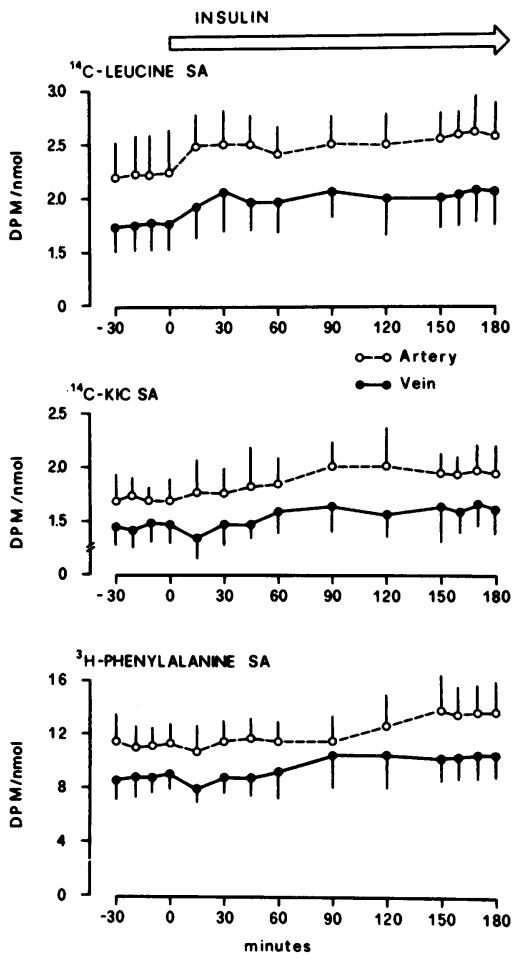

Figure 2. Plasma $\left[{ }^{14} \mathrm{C}\right]$ leucine, $\left[{ }^{14} \mathrm{C}\right] \mathrm{KIC}$, and $\left[{ }^{3} \mathrm{H}\right]$ phenylalanine specific activities (DPM/ nmol), before and during the insulin infusion in the artery (open circles and dotted lines) and in the deep vein (closed circles and continued lines). 
acid, injected into the HPLC, within the ranges achieved in this study was obtained. KIC concentration and SA were also measured by HPLC as referenced (16). Most samples were run in duplicates. Plasma insulin and glucose were determined as reported in (5). The concentrations of intermediary metabolites in the whole blood were measured as reported in (18). Plasma free fatty acid concentrations were determined by an enzymatic method (19).

Determination of plasma flow. Plasma flow was determined with the dye-dilution method as described in $(15,20)$. Indocyanine green (Cardiogreen; Hynson, Westkott \& Dunning, Baltimore, MD) was dissolved with $0.9 \%$ saline containing $5 \%$ albumin. The dye was infused directly into the arterial catheter for $5 \mathrm{~min}$ before each blood flow determination, by means of a calibrated pump. During this period, the flow of the hand was excluded with a pediatric sphingomanometer placed around the wrist and inflated at $170-180 \mathrm{mmHg}$. Samples for plasma flow analysis were collected very slowly from the deep vein to avoid perturbation of flow. The concentrations of the dye in the infusate after proper dilution, as well as in the serum samples, were determined spectrophotometrically at $510 \lambda$. Recirculation of the dye was quantitated with a sample taken from a vein of the opposite arm, and found to be negligible $(<5 \%)$. The values of the two baseline, as well as those of the two postinsulin samples, were averaged to obtain the plasma flow values before and after the start of the insulin infusion. Forearm mass $(\approx$ forearm vol) was measured by water displacement

Calculations and statistical analyses. All kinetic measurements were performed at steady state of plasma concentrations and specific activities effectively attained in the last $30 \mathrm{~min}$ of the basal period, as well as in the last $30 \mathrm{~min}$ of the insulin infusion period (Figs. 1 and 2). Whole-body phenylalanine and leucine $R_{\mathrm{a}}$ were calculated using the arterial plasma SA and conventional equations $(10,21,22)$. Leucine $R$ was calculated using both the "primary" and the "reciprocal pool" model (13). Forearm uptake of phenylalanine and of leucine were calculated by applying the following equation:

$\frac{\frac{D P M_{\mathrm{a}}}{\mathrm{ml}}-\frac{D P M_{\mathrm{v}}}{\mathrm{ml}}}{S A_{\mathrm{a}}} \times F \times \frac{1}{V}$

where: $D P M_{\mathrm{a}} / \mathrm{ml}$ is radioactivity concentration in the artery; $D P M_{\mathrm{v}} / \mathrm{ml}$ is radioactivity concentration in the deep vein; $S A_{\mathrm{a}}$ is the specific activity (DPM/nmol) in the artery; $F$ is plasma flow, expressed as milliliters per minute; and $V$ is the forearm mass (expressed in grams).

Amino acid release was then calculated by adding the arterial deep venous difference to uptake. The difference between the arterial and the deep venous concentrations of leucine, KIC, isoleucine, and phenylalanine were also analyzed by introducing a correction for the calculated delay in equilibration of the venous concentration, due to dilution within the extracellular muscular space during the insulin infusion period, i.e., at a time when concentrations changed over time. This "delay," or "correction," is represented by the mean transit time (MTT) that each molecule has to spend to travel across the extracellular muscular space. This MTT is calculated by dividing the extracellular space of muscle tissue (expressed as milliliters per kilogram muscle) by the estimated plasma flow through the muscle fibers (expressed as milliliters per kilogram per min) (23). Of course, this approach does not account for the intracellular diffusion and equilibration of these molecules. In fact, it may be possible that a response to the hypoaminoacidemic effect of insulin is more prompt intracellularly, but it becomes manifested only later in the deep venous plasma. However, in our opinion, the interpretation of changes in net organ balance of a substrate does not need to account for its intracellular exchange, when one measures systemic changes in concentrations and the net forearm output of a substrate. In addition, it is likely that a considerable fraction of leucine (and of phenylalanine) delivered with the arterial blood supply bypasses its intracellular metabolism, i.e., it behaves as metabolically inactive. This fraction has been recently estimated to represent as much as $\approx 60 \%$ of the arterial leucine supply in the catheterized dog gut in vivo (24). Even though this figure is not yet available as regards muscle, such a possibility cannot be dismissed. In any case, the description of the overall picture of extracellular as well as intracellular amino acid kinetics under non-steady-state conditions, in the whole body as well as across the cell membrane of individual tissues, is not yet available, and it will probably require a remarkable effort both from the experimental and the mathematical point of view. The solution of these complex problems may represent the most stimulating task in this field for the following years.

This calculation of MTT has recently been used as regards glucose metabolism in the human forearm (23), and it yields an estimate of MTT comparable to that calculated by a compartmental model applied to L-glucose that is not transported inside the cell (23) and therefore diffuses only extracellularly. Since MTT is dependent on extracellular muscular space and on forearm muscle plasma flow, it must be valid as regards the extracellular equilibration for every substrate, i.e., glucose, amino acids, etc. MTT that is expressed in minutes corresponds therefore to the time required by plasma to clear the whole extracellular muscle space.

To calculate MTT, forearm muscle mass was assumed to represent $60 \%$ of forearm mass (25), and the extracellular space pertaining to muscle was assumed, from literature data, to be $95.8 \mathrm{ml} / \mathrm{kg}$ muscle (23, 25). Plasma flow through muscle fibers was calculated by multiplying total forearm plasma flow by the factor $(0.47 \times$ total forearm plasma flow +8.3$)(25)$. The original HPLC-measured, arterial as well as deep venous, leucine, $\mathrm{KIC}$, isoleucine, and phenylalanine concentrations of each subject were used to fit a curvilinear plot of both the arterial and venous concentrations before and during the insulin infusion, using a computer program (Harvard Graphics, Software Publishing Co., 1987). Thereafter, the venous values at each time point, increased by each individual's mean transit time, were identified along each plotted line. Using this correction, the so-calculated venous values were compared for the statistical analysis with the arterial values also identified along the best fit curve at the corresponding time point. In other words, the time points of the arterial values along the best fit curve were those of the actual sampling time, while those of the deep vein, also identified along the fitted curve, were increased by each subject's MTT.

The area under the curve of both the arterial and the venous values was also calculated using conventional computer programs. For the statistical analysis, the two-tailed paired $t$ test was employed to test arterial vs. deep venous concentration data, as well as the concentration and the kinetic values after vs. before insulin. In addition, the steady-state kinetic data (after vs. before insulin) were analyzed using the one way analysis of variance (ANOVA) for replicated measures. However, since under these conditions of only one replication the square root of the $F$ value is equal to the $t$ value of the paired $t$ test, we do not report the ANOVA analysis. A $P$ value equal to or less than 0.05 was taken as statistically significant. All data have been expressed as mean \pm SE

\section{Results}

Substrate concentrations and specific activities. Plasma insulin increased from $8 \pm 1 \mu \mathrm{U} / \mathrm{ml}$ of the basal, postabsorptive state to $75 \pm 6 \mu \mathrm{U} / \mathrm{ml}$ after the insulin infusion $(P<0.01)$. Plasma glucose concentrations were $85 \pm 2 \mathrm{mg} / \mathrm{dl}$ in the basal state and were maintained at the same level throughout the study (data not shown). In the basal state, leucine, isoleucine, and KIC concentrations were significantly greater $(P<0.01)$ in the deep venous plasma than in the arterial one, indicating a small but significant net substrate output by the forearm (leucine $=-4.8 \pm 1.6 ;$ isoleucine $=-5.1 \pm 1.7 ; \mathrm{KIC}=-3.0 \pm 0.9 \mu \mathrm{mol} /$ liter) (Table I). Deep venous phenylalanine concentrations were also slightly, even if not significantly, greater than in the artery (arterial/deep venous difference: $-4.6 \pm 2.1 \mu \mathrm{mol} / \mathrm{liter}$ ), this difference approaching statistical significance $(t=2.17, P$ 
Table II. Arterial and Deep-Venous Leucine, KIC, Isoleucine, and Phenylalanine Concentrations Calculated According to a Best Fit Curve through the Individual Values (See Methods)

\begin{tabular}{|c|c|c|c|c|c|c|c|c|c|c|}
\hline Time (min) & & $-30-0$ & +15 & +30 & +45 & +60 & +90 & +120 & $+150-180$ & AUC \\
\hline \multirow{2}{*}{$\begin{array}{l}\text { Leucine } \\
\qquad(\mu \mathrm{mol} / \text { liter })\end{array}$} & A & $140 \pm 4$ & $138 \pm 4$ & $131 \pm 3$ & $128 \pm 3$ & $110 \pm 4$ & $110 \pm 4$ & $101 \pm 3$ & $95 \pm 4$ & $17481 \pm 444$ \\
\hline & $\mathrm{dV}$ & $145 \pm 5^{*}$ & $144 \pm 4^{*}$ & $140 \pm 4^{*}$ & $135 \pm 4^{*}$ & $126 \pm 3^{*}$ & $113 \pm 4^{*}$ & $103 \pm 3$ & $94 \pm 4$ & $18084 \pm 528^{*}$ \\
\hline \multirow{2}{*}{$\begin{array}{l}\mathrm{KIC} \\
\quad(\mu \mathrm{mol} / \text { liter })\end{array}$} & A & $40 \pm 2$ & $40 \pm 3$ & $39 \pm 3$ & $37 \pm 3$ & $34 \pm 2$ & $29 \pm 2$ & $26 \pm 2$ & $25 \pm 2$ & $4820 \pm 320$ \\
\hline & $d V$ & $43 \pm 2^{*}$ & $43 \pm 3^{*}$ & $42 \pm 3^{*}$ & $40 \pm 3^{*}$ & $38 \pm 3^{*}$ & $32 \pm 2^{*}$ & $28 \pm 2^{*}$ & $26 \pm 2$ & $5216 \pm 322^{*}$ \\
\hline \multirow{2}{*}{$\begin{array}{l}\text { Isoleucine } \\
\quad(\mu \mathrm{mol} / \text { liter })\end{array}$} & A & $42 \pm 2$ & $42 \pm 3$ & $40 \pm 4$ & $36 \pm 3$ & $33 \pm 4$ & $28 \pm 4$ & $21 \pm 3$ & $16 \pm 2$ & $4525 \pm 462$ \\
\hline & $d V$ & $47 \pm 4^{*}$ & $46 \pm 5^{*}$ & $45 \pm 5^{*}$ & $40 \pm 3^{*}$ & $36 \pm 3^{*}$ & $29 \pm 4$ & $23 \pm 3^{\ddagger}$ & $17 \pm 2$ & $4930 \pm 500^{*}$ \\
\hline \multirow{2}{*}{$\begin{array}{r}\text { Phenylalanine } \\
(\mu \mathrm{mol} / \text { liter })\end{array}$} & A & $44 \pm 5$ & $43 \pm 4$ & $41 \pm 4$ & $40 \pm 4$ & $37 \pm 4$ & $35 \pm 4$ & $31 \pm 3$ & $29 \pm 3$ & $5438 \pm 532$ \\
\hline & $d \mathbf{V}$ & $48 \pm 5^{\ddagger}$ & $50 \pm 5^{*}$ & $49 \pm 4^{*}$ & $47 \pm 4^{*}$ & $44 \pm 3^{*}$ & $36 \pm 4$ & $32 \pm 3^{*}$ & $30 \pm 3$ & $6041 \pm 538^{*}$ \\
\hline
\end{tabular}

Deep venous values were extrapolated along the curve by correcting for each individual's mean transit time across the estimated extracellular muscular space. AUC throughout the study period are also reported. Basal (i.e., from -30 to $0 \mathrm{~min}$ ) as well as postinsulin (from 150 to 180 min) values were averaged. All values are mean $\pm \mathrm{SE}^{*}{ }^{*} P<0.05$ or less; ${ }^{\ddagger} P<0.07$; deep venous vs. arterial values. $A$, arterial; $\mathrm{dV}$, deep venous.

$<0.07$ ) (Table I). 30-60 min after the start of insulin, significant decrements with respect to basal values in the arterial concentrations of leucine, KIC, and phenylalanine were detected (Fig. 1). However, deep venous plasma concentrations of all substrates remained greater $(P<0.05-P<0.001)$ than the arterial concentrations at almost each time point during the insulin infusion (Fig. 1). Isoleucine levels followed the same pattern (data not shown). By the end of insulin, percent arterial decreases of leucine, KIC, isoleucine, and phenylalanine concentrations were $\approx 38, \approx 38, \approx 61 \%$, and $\approx 34 \%$, respectively, vs. baseline. After insulin, the concentrations in the deep venous plasma were not statistically different from those of the artery (Table I, Fig. 1).

The calculated arterial and deep venous plasma concentrations of leucine, $\mathrm{KIC}$, isoleucine, and phenylalanine, using the best fit computer program and the corrections, as regards the venous values, for the estimated mean transit time across muscle fibers, are reported on Table II. The average mean transit time across the extracellular muscle space was $3.13 \pm 0.52 \mathrm{~min}$. Even with this correction, during the insulin infusion deep venous concentrations were consistently greater than the corresponding arterial ones at least for the first $90 \mathrm{~min}$ (Table II). Also the area under the curve (AUC) of the deep venous values, corrected for the mean transit time, were all statistically greater than the arterial areas for leucine, KIC, isoleucine, and phenylalanine (Table II).

Plasma leucine, $\mathrm{KIC}$, and phenylalanine SA were greater in the artery than in the vein throughout the study (Fig. 2). This

Table III. Whole-Body Leucine and Phenylalanine $R_{a}$ at Steady State before and after Insulin Infusion

\begin{tabular}{|c|c|c|c|}
\hline & \multicolumn{2}{|c|}{ Leucine $R_{a}$} & \multirow{2}{*}{$\frac{\text { Phenylalanin }}{R_{\mathrm{a}}}$} \\
\hline & Primary pool & Reciprocal pool & \\
\hline Before insulin & $2.03 \pm 0.26$ & $2.70 \pm 0.23$ & $0.73 \pm 0.08$ \\
\hline After insulin & $1.76 \pm 0.25^{*}$ & $2.34 \pm 0.24^{*}$ & $0.57 \pm 0.05^{*}$ \\
\hline
\end{tabular}

The leucine data have been calculated using both the primary and the reciprocal pool model (see ref. 13). The kinetic data are expressed as micromoles per kilogram times minutes. ${ }^{*} P<0.01$, after vs. before insulin. pattern, at variance with respect to that observed for the concentrations (Tables I and II, Fig. 1) indicated a simultaneous release and uptake of these amino acids and of KIC. Arterial plasma $\left[{ }^{14} \mathrm{C}\right]$ leucine, $\left[{ }^{14} \mathrm{C}\right] \mathrm{KIC}$ and $\left[{ }^{3} \mathrm{H}\right]$ phenylalanine SA increased $(P<0.01)$ after the start of insulin, reaching a steadystate value by the end of the hormone infusion (Fig. 2). Plasma flow in the postabsorptive state was $27.3 \pm 4.5 \mathrm{ml} / \mathrm{min}$, and it did not significantly change after insulin (to $33.2 \pm 3.4 \mathrm{ml} / \mathrm{min}$ ).

Whole-body and forearm leucine and phenylalanine $k i-$ netics. Whole-body leucine $R_{\mathrm{a}}$ (primary as well as reciprocal pool model calculations) and phenylalanine $R_{\mathrm{a}}$ decreased significantly $(P<0.01)$ by $\approx 13 \%, \approx 13 \%$, and $\approx 22 \%$, respectively, after vs. before insulin (Table III). In the basal state, forearm leucine release was significantly greater $(P<0.01)$ than uptake, thus resulting as reported above, in a net output of this amino acid (Table IV). Phenylalanine release was slightly but not significantly greater $(t=2.17, P<0.07)$ than uptake (Table IV). After insulin, both uptake and release of leucine by the forearm decreased with respect to baseline by $\approx 10 \%$ and by $\approx 26 \%$, respectively. However, these changes did not achieve statistical significance because of two crossover values as regards the former parameter, and one as regards the latter. Similarly, phenylalanine uptake and release decreased by $\approx 7 \%$ and by $\approx 23 \%$, respectively (Table IV), but, again, these changes were not significant, because of an even larger disomogeneity in the directions of changes (three vs. four). However, by the end of the insulin infusion, uptake of both leucine and phenylalanine

Table IV. Forearm Uptake and Release of Leucine and Phenylalanine before and after Insulin at Steady State

\begin{tabular}{llc}
\hline & \multicolumn{1}{c}{ Before insulin } & After insulin \\
\hline & \multicolumn{1}{c}{$\mu \mathrm{mol} / \mathrm{min} \cdot \mathrm{kg}$ forearm } \\
Leucine data & & \\
Uptake & & $0.579 \pm 0.092$ \\
Release & $0.640 \pm 0.150$ & $0.541 \pm 0.057$ \\
Phenylalanine data & $0.735 \pm 0.150^{*}$ & \\
$\quad$ Uptake & & $0.201 \pm 0.059$ \\
Release & $0.215 \pm 0.068$ & $0.238 \pm 0.049$
\end{tabular}

\footnotetext{
${ }^{*} P<0.01$ uptake vs. release.
} 
were no longer statistically different from the corresponding release values (Table IV).

After extrapolation to whole-body muscle mass $(15,23,24$, 26), leucine release by muscle tissues, expressed as percent of whole-body $R_{\mathrm{a}}$ (primary pool model), did not change before $(24 \pm 6 \%)$ vs. after insulin $(20 \pm 3 \%)$; similarly, percent phenylalanine release by total skeletal muscle was also unaltered $(29 \pm 7 \%$ to $28 \pm 7 \%$, respectively).

Intermediary metabolites. The arterial concentrations of some intermediary metabolites are reported on Table V. Lactate concentrations increased; those of glycerol, $\beta$-hydroxybutyrate, free fatty acids, and some amino acids decreased, after the start of the insulin infusion.

\section{Discussion}

In this study we show that the acute induction of systemic hyperinsulinemia reduces whole-body concentrations and rate of appearance of two essential amino acids, leucine and phenylalanine, without affecting either their net output by the forearm (i.e., the difference between arterial and deep venous concentrations), at least during the first $2 \mathrm{~h}$ of the insulin infusion, or their steady-state kinetics (i.e., both uptake and release) at the forearm level, before vs. after insulin. Since the forearm mass is mainly represented by muscle (25), our data indicate that muscle is not the most immediate target site of this insulin action. Therefore, under the commonly accepted assumption that release into the circulation of essential amino acids reflects proteolysis $(10,21,22)$, our data suggest that the early inhibition of whole-body protein degradation by systemic hyperinsulinemia does not take place at the level of skeletal muscle.

Our findings are quite surprising and in apparent contrast with literature data $(8,27,28)$. Previous studies performed with the infusion of insulin directly into the brachial artery indeed showed that insulin inhibited the release of essential amino acids by the forearm and improved their net balance $(8,27,28)$. The aim of those experiments was to study the effects of a single variable, i.e., a local increase in insulin levels on forearm amino

Table V. Arterial Concentrations of Intermediary Metabolites and Selected Amino Acids before and after Insulin Infusion

\begin{tabular}{|c|c|c|}
\hline & Before insulin & After insulin \\
\hline & \multicolumn{2}{|c|}{$\mu \mathrm{mol} / \mathrm{liter}$} \\
\hline Lactate & $0.545 \pm 0.042$ & $0.915 \pm 0.083^{*}$ \\
\hline Pyruvate & $0.022 \pm 0.005$ & $0.039 \pm 0.009$ \\
\hline Glycerol & $0.083 \pm 0.017$ & $0.060 \pm 0.016^{*}$ \\
\hline$\beta$-Hydroxybutyrate & $0.083 \pm 0.017$ & $0.035 \pm 0.006^{*}$ \\
\hline Acetoacetate & $0.139 \pm 0.011$ & $0.125 \pm 0.017$ \\
\hline Free fatty acids & $0.390 \pm 0.087$ & $0.050 \pm 0.012^{*}$ \\
\hline Lysine & $190 \pm 37$ & $155 \pm 27^{*}$ \\
\hline Isoleucine & $49 \pm 8$ & $23 \pm 6^{*}$ \\
\hline Valine & $271 \pm 28$ & $198 \pm 21^{*}$ \\
\hline Tryptophane & $54 \pm 17$ & $37 \pm 12^{*}$ \\
\hline Proline & $424 \pm 39$ & $237 \pm 47$ \\
\hline Alanine & $454 \pm 39$ & $474 \pm 30$ \\
\hline Glycine & $293 \pm 41$ & $270 \pm 39 *$ \\
\hline Serine & $154 \pm 22$ & $134 \pm 11$ \\
\hline
\end{tabular}

${ }^{*} P<0.05$ or less, before vs. after insulin infusion. acid uptake and release without any change in systemic hormone as well as substrate (amino acids, free fatty acids, ketone bodies) concentrations. It is quite possible that the maintenance of basal substrate concentrations, above all amino acids, allowed the effects of local hyperinsulinemia on leucine and phenylalanine release by the forearm to be fully manifested. In contrast, in our study arterial leucine and phenylalanine concentrations were allowed to decrease, thus possibly preventing an effect of insulin also at the forearm level. In fact, recent reports have underscored the major role of amino acid levels in conditioning their own utilization in the whole body independently from insulin concentrations $(4-6,29)$. These considerations, however, do not explain why, under conditions of a more physiological, systemic insulin infusion like those of our study, arterial leucine and phenylalanine concentrations and $R_{\mathrm{a}}$ decreased, despite no active increase in their uptake nor a significant decrease in their release by the forearm. Therefore, other organs and/or tissues, which may respond to insulin more promptly than skeletal muscle and, possibly, not depending on circulating amino acid levels, must be the more immediate target sites of the systemic effects of the hormone.

In the attempt to identify these sites from a functional if not an anatomical point of view, a first consideration should be made. The half-life of most visceral proteins is quite fast, from minutes to a few hours (10); therefore they may respond more promptly to insulin. Moreover, under stress conditions, wholebody amino acid (and protein) catabolism increases, but the concentrations and the rate of synthesis of some acute-phase hepatic proteins (i.e., fibrinogen and other globulins) increase (10). More recently, it has been shown that during insulin-induced hypoglycemia, leucine concentration and $R_{\mathrm{a}}$ decrease at first, but then they increase again, because of an increased release of this amino acid by the splanchnic region (30). Therefore, it is conceivable that some dissociation between organs may occur as regards the proteolytic response to certain stimuli, and that visceral organs and/or short-lived proteins, besides accounting for a significant portion of whole-body amino acid disposal and turnover $(10,31)$, may also respond more quickly to a variety of stimuli, including insulin. Of course, this hypothesis needs to be substantiated by direct experimental evidence.

The conclusions of our study are based upon data obtained both in the steady-state and in the non-steady-state experimental periods. Indeed, as regards the kinetic data, uptake and release of both leucine and phenylalanine, calculated at steady state before and at the end of hormone administration, showed a variable decrease after insulin; however, these changes did not achieve statistical significance (see Results). Failure to attain a significant difference does not depend on the number of subjects studied (seven), as indicated also by the phenylalanine data (see Results). Since phenylalanine is not metabolized by muscle (9-11), (i.e., its uptake represents incorporation into protein), the kinetic data of this amino acid appear confirmatory of those of leucine, and strongly support our conclusions. In any case, the view that insulin eventually exerted some effect on muscle amino acid metabolism may not be excluded. In fact, after the insulin infusion, percent leucine as well as phenylalanine release by the forearm were decreased grossly to a larger extent than their uptake; moreover, the net arterial, deep venous differences of leucine, $\mathrm{KIC}$, isoleucine, and phenylalanine were no longer different from zero at the end of the insulin infusion. In addition, the extrapolation to whole-body skeletal 
muscle mass showed no change in percent leucine as well as phenylalanine release by total skeletal muscle with respect to whole-body $R_{\mathrm{a}}$. These data indicate a coordinated decrease in the release of essential amino acids from proteolysis occurring at several sites but with a different time pattern. Therefore, on the whole, these findings may indicate that amino acid (and protein) turnover in the forearm were eventually decreased by hyperinsulinemia (after $2 \mathrm{~h}$ ). Alternatively, this late suppression at the forearm level in the net output, as well as in $R_{\mathrm{a}}$, of essential amino acids, observed at the end of insulin, might have occurred because whole-body turnover and concentrations also decreased, i.e., the arterial supply of amino acids to the forearm was decreased. Since in the early period of the insulin infusion the forearm did not switch from output to net uptake of these essential amino acids, the latter hypothesis cannot be excluded but, actually, it seems more likely.

As regards the non-steady-state portion of the study, i.e., during the acute decrease of leucine and phenylalanine concentrations, the interpretation of kinetic data is limited since no validated model exists at present to calculate amino acid uptake and release under these conditions. Therefore, only the net arterial deep venous difference, i.e., the net output of leucine, $\mathrm{KIC}$, phenylalanine, and, in this case, also of isoleucine, by the forearm, can retain a physiological meaning. Again, these data do not show any role of the forearm in the net removal of these three essential amino acids and of KIC after the acute induction of systemic hyperinsulinemia. This conclusion is confirmed also after the correction of the data for the estimated delay of equilibration of the venous concentrations, due to dilution within the extracellular muscular space (see Methods).

In the postabsorptive state, the net output of the three essential amino acids by the forearm indicated that skeletal muscle contributed to some extent to the maintenance of their systemic levels, as suggested years ago by Pozefsky and colleagues (27). Consequently, it suggests also that net amino acid removal occurs at extramuscular sites in the postabsorptive state, at steady-state conditions. Arterial and deep venous forearm concentrations of amino acids are therefore dependent upon each other. Theoretically, the decrease of the arterial levels might have been the consequence of a possible insulin-induced suppression of forearm net amino acid release into the deep venous plasma, resulting in systemic amino acid levels no longer sufficient to maintain the basal, preinsulin arterial concentrations. Alternatively, deep venous concentrations decreased because arterial levels decreased. It is clear that the choice between these two hypotheses requires a careful analysis of the time-dependency of the observed phenomena across the forearm, as well as across other in vivo accessible districts. In this study, only forearm amino acid exchange was measured. From the data of Fig. 1, as well as from the deep venous data corrected for the mean transit time within the extracellular muscular space (Table II), the last hypothesis that is key in the overall conclusion of our study appears to be the most acceptable. Of course, it would be extremely interesting to measure also splanchnic amino acid exchange under the same experimental conditions.

Other metabolic interactions must also be considered. Since increased free fatty acid concentrations have been shown to decrease leucine release in the whole body in dogs (32), as well as at the forearm level in humans (33), and increased ketone body concentrations, in particular $\beta$-hydroxybutyrate, have been shown to stimulate whole-body and muscle protein synthesis (34), the decrease of free fatty acid and ketone body concentrations during insulin might have offset a possible stimulating effect of the hormone itself on amino acid deposition within the forearm. This hypothesis needs to be tested in further studies.

Our data extend to skeletal muscle previous findings obtained in the whole body (4-6) that suggested that the in vivo utilization of an essential amino acid, like leucine, is not stimulated by insulin. The utilization of leucine, both in the whole body and at organ level, appears therefore to depend mainly on the circulating levels of this amino acid $(5,6)$. The lack of any stimulatory effect of insulin on leucine and phenylalanine uptake is paralleled by the in vitro demonstration of no enhancement by insulin of amino acid L-transport system (35), which is specific, among other essential amino acids, also for leucine and phenylalanine (36). Recently, we have reported that in type 1 diabetic patients studied after an overnight insulin withdrawal and a subsequent intravenous insulin infusion, leucine and KIC uptake and release by the forearm were not affected by a peripheral insulin infusion, in the face of a marked reduction in systemic leucine and KIC concentration and $R_{\mathrm{a}}(26)$. Those data, therefore, were qualitatively similar to what was observed in this study in normal volunteers. In that protocol, however, we could not exclude that the presence of insulin resistance, hyperglycemia, and/or other metabolic disturbances due to the preceding insulin lack possibly antagonized the effects of insulin at the forearm level. Moreover, a phenylalanine tracer was not used. In this study we confirm the validity of that observation also in normal subjects, under more controlled conditions and with the aid of a simultaneous infusion of tracers of two essential amino acids. A direct comparison between the effects observed in type 1 diabetes and in normal subjects is however not possible, due to the different levels of amino acids and of insulin achieved in the two protocols (26).

In conclusion, our study indicates that little of the systemic effects of acute hyperinsulinemia on amino acid metabolism occurs at the level of skeletal muscle, therefore indirectly underscoring the role of extramuscular districts as the immediate targets of these insulin effects. This observation may be relevant as regards both the understanding of the physiology of insulin action in vivo and the design of parentheral nutritions regimens that include also insulin.

\section{Acknowledgments}

This study was supported in part by a grant of a Target Project of the National Research Council of Italy (CNR), entitled "Biotechnology and Bioinstrumentations."

\section{References}

1. Abumrad, N. N., L. S. Jefferson, S. R. Rannels, P. E. Williams, A. D. Cherrington, and W. W. Lacy. 1982. Role of insulin in the regulation of leucine kinetics in the conscious dog. J. Clin. Invest. 70:1031-1041.

2. Fukagawa, N. K., K. L. Minaker, J. W. Rowe, M. N. Goodman, D. E. Matthews, D. M. Bier, and V. R. Young. 1985. Insulin-mediated reduction of whole-body protein breakdown. Dose-response effects on leucine metabolism in postabsorptive men. J. Clin. Invest. 76:2306-2311.

3. Tessari, P., R. Trevisan, S. Inchiostro, S. Vigili de Kreutzenberg, G. Biolo, E. Duner, A. Tiengo, and G. Crepaldi. 1986. Dose-response curves of the effects of insulin on leucine kinetics in man. Am. J. Physiol. 251:E334-E343.

4. Umpleby, A. M., M. A. Boroudjerdi, P. M. Brown, E. R. Carson, and P. E. Sönsken. 1986. The effect of metabolic control on leucine metabolism in type 1 (insulin-dependent) diabetic patients. Diabetologia. 29:131-141.

5. Tessari, P., S. Inchiostro, G. Biolo, R. Trevisan, G. Fantin, M. C. Mare- 
scotti, E. Iori, A. Tiengo, and G. Crepaldi. 1987. Differential effects of hyperinsulinemia and hyperaminoacidemia on leucine-carbon metabolism in vivo. Evidence for distinct mechanisms in regulation of net amino acid deposition. J. Clin. Invest. 79:1062-1069.

6. Castellino, P., L. Luzi, D. C. Simonson, M. Haymond, and R. A. DeFronzo. 1987. Effect of insulin and plasma amino acid concentration on leucine metabolism in man: role of substrate availability on estimates of whole body protein synthesis. J. Clin. Invest. 80:1784-1793.

7 . Robert, J. J., B. Beaufrere, J. Kosiet, J. F. Desjeux, D. M. Bier, V. R. Young and $H$. Lestradet. 1985. Whole-body de novo amino acid synthesis in type 1 (insulin-dependent) diabetes studied with stable-isotope labelled leucine, alanine and glycine. Diabetes. 34:67-73.

8. Gelfand, R., and E. J. Barrett. 1987. Effect of physiologic hyperinsulinemia on skeletal muscle protein synthesis and breakdown. J. Clin. Invest. 80:1-6.

9. Barrett, E., J. Revkin, L. Young, B. Zaret, R. Jacob, and R. Gelfand. 1987 An isotopic method for in vivo measurement of muscle protein synthesis and degradation. Biochem. J. 245:223-228.

10. Waterlow, J. C., P. J. Garlick, and D. J. Millward. 1978. Protein turnove in mammalian tissues and in the whole-body. North-Holland Publishing Co., Amsterdam.

11. Rosenberg, L. E., and C. R. Scriver. 1980. Disorders of amino acid metabolism. In Metabolic Control and Disease. P. K. Bondy and L. E. Rosenberg, editors. W. B. Saunders Co., Philadelphia. 707-710.

12. Matthews, D. E., H. P. Schwarz, R. D. Yang, K. J. Motil, V. R. Young, and D. M. Bier. 1982. Relationship of plasma leucine and $\alpha$-ketoisocaproate during a $L-{ }^{13} \mathrm{C}$ leucine infusion in man: a method for measuring human intracellular tracer enrichment. Metab. Clin. Exp. 31:1105-1112.

13. Schwenk, W. F., B. Beaufrere, and M. W. Haymond. 1985. Use of reciprocal pool specific activities to model leucine metabolism in humans. Am. J. Physiol. 249:E646-E650.

14. Shinnick, F. L., and A. L. Harper. 1976. Branched-chain amino acid oxidation by isolated rat tissue preparations. Biochim. Biophys. Acta. 437:477486.

15. Andres, R. K, L. Zierler, H. M. Anderson, W. N. Stainsby, G. Cader, A. S. Ghrayyib, and J. L. Lilienthal. 1954. Measurement of blood flow and volume in the forearm of man: with note on the theory of indicator-dilution and on production of turbolence, hemolysis and vasodilatation by intravascular injection. $J$. Clin. Invest. 33:482-504.

16. Nissen, S. L., C. Van Huysen, and M. W. Haymond. 1982. Measurement of branched-chain amino acids and branched-chain $\alpha$-ketoacids in plasma by high performance liquid chromatography. J. Chromatogr. 232:170-175.

17. Tessari, P., S. Inchiostro, M. Vettore, M. C. Marescotti, and G. Biolo. 1992. A rapid HPLC method for the measurement of plasma phenylalanine concentration and specific activity Clin. Biochem. In press.

18. Trevisan, $R$, R. Nosadini, A. Avogaro, G. Lippe, E. Duner, P. Fioretto, $R$ Deana, P. Tessari, A. Tiengo, M. Velussi, et al. 1986. Type 1 diabetes is characterized by insulin-resistance not only with regard to glucose but also to lipid and amino acid metabolism. J. Clin. Endocrinol. \& Metab. 62:1152-1162.

19. Shimuzu, S., K. Inohue, Y. Tani, and H. Yamada. 1979. Enzymatic microdetermination of serum free fatty acids. Anal. Biochem. 98:341-345.
20. Capaldo, B., D. Santoro, G. Riccardi, N. Perrotti, and L. Saccà. 1986. Direct evidence for a stimulatory effect of hyperglycemia per se on peripheral glucose disposal in type II diabetes. J. Clin. Invest. 77:1285-1290.

21. Bier, D. M. 1989. Intrinsically difficult problems: the kinetics of body proteins and amino acids in man. Diabetes Metab. Rev. 5:111-132.

22. Umpleby, A. M., and P. H. Sonsken. 1987. Measurement of the turnover of substrates of carbohydrate and protein metabolism using radioactive isotopes. In Baillière's Clinical Endocrinology and Metabolism. Vol. 1. 773-797.

23. Cobelli, C., M. P. Saccomani, E. Ferrannini, R. A. DeFronzo, R. Gelfand, and $R$. Bonadonna. 1989. A compartmental model to quantitate in vivo glucose transport in the human forearm. Am. J. Physiol. 257:E943-E958.

24. Yong-Ming, Y., D. A. Wagner, E. E. Tredget, J. A. Walaszewsky, J. F. Burke, and V. R. Young. 1990. Quantitative role of splanchnic region in leucine

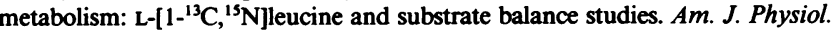
259:E36-E51.

25. Cooper, K., O. Edholm, and R. Mottram. 1955. The blood flow in skin and muscle in the human forearm. J. Physiol. (Lond.). 128:258-267.

26. Tessari, P., G. Biolo, S. Inchiostro, L. Saccà, M. T. Boscarato, R. Trevisan, S. Vigili de Kreutzenberg, R. Nosadini, and A. Tiengo. 1990. Effects of hyperinsulinemia on forearm leucine and $\mathrm{KIC}$ kinetics in type 1 diabetes. Am. J. Physiol. 259:E96-E103.

27. Pozefsky, T., P. Felig, J. D. Tobin, J. Stuart-Soeldner, and G. F. Cahill. 1969. Amino acid balance across tissues of the forearm in postabsorptive man. Effects of insulin at two dose levels. J. Clin. Invest. 48:2273-2282.

28. Sherwin, R. S. 1981. Amino acid and protein metabolism in normal and diabetic humans. In Handbook of Diabetes Mellitus. Vol. 3: Intermediary Metabolism and Its Regulation. M. Brownlee, editor. Garland STPM Press, New York and London. 1-47.

29. Pacy, P. J., K. S. Nair, C. Ford, and D. Halliday. 1989. Failure of insulin infusion to stimulate fractional muscle protein synthesis in type 1 diabetic patients. Diabetes. 38:618-624.

30. Hourani, H., P. Williams, J. A. Morris, M. E. May, and N. N. Abumrad. 1990. Effect of insulin-induced hypoglycemia on protein metabolism in vivo. Am. J. Physiol. 259:E342-E350.

31. Gelfand, R. A., M. G. Glickman, P. Castellino, R. J. Louard, and R. A. DeFronzo. 1988. Measurement of $\mathrm{L}-\left[1-{ }^{14} \mathrm{C}\right]$ leucine kinetics in splanchnic and leg tissues in humans. Diabetes. 37:1365-1372.

32. Tessari, P. S. L. Nissen, J. M. Miles, and M. W. Haymond. 1986. Inverse relationship of leucine flux and oxidation to free fatty acid availability in vivo. $J$. Clin. Invest. 77:575-581.

33. Wicklmayr, M., K. Rett, B. Schwiegelsohn, G. Wolfram, S. Hailer, and G. Dietze. 1987. Inhibition of muscular amino acid release by lipid infusion in man. Eur. J. Clin. Invest. 17:301-305.

34. Nair, S. K., S. L. Welle, D. Halliday, and R. G. Campbell. 1988. Effect of $\beta$-hydroxybutyrate on whole-body leucine kinetics and fractional mixed skeletal muscle protein synthesis in humans. J. Clin. Invest. 82:198-205.

35. Guidotti, G. G., A. F. Borghetti, and G. C. Gazzola. 1978. The regulation of amino acid transport in animal cells. Biochim. Biophys. Acta. 515:329-366.

36. Christensen, H. N. 1982. Interorgan amino acid nutrition. Physiol. Rev. 62:1194-1233. 